\title{
A Literature Review through the Lens of Computer Science Learning Goals Theorized and Explored in Research
}

\author{
Kathryn Rich \\ UChicago STEM Education \\ University of Chicago \\ kmrich@uchicago.edu
}

\author{
Carla Strickland \\ UChicago STEM Education \\ University of Chicago \\ castrickland@uchicago.edu
}

\author{
Diana Franklin \\ UChicago STEM Education \\ University of Chicago \\ dmfranklin@uchicago.edu
}

\begin{abstract}
Research on appropriate topics and goals for computer science (CS) education in elementary and middle school has been ongoing for decades, but the recent movement toward CS for all requires the research community to gain a better understanding of what is most important to teach, to whom, and in what order. We conducted a literature review with specific attention to cataloging computer science learning goals that experts theorize are important to teach as well as learning goals that have been explored and researched with students in K-8. By mapping the former onto the latter, we discovered six categories of goals that are theorized as important but, according to our review, are yet to be researched with $\mathrm{K}-8$ students. We discuss the potential implications of these gaps for future research.
\end{abstract}

\section{Keywords}

Elementary school; Middle school; Computer science learning goals; Classroom research

\section{INTRODUCTION}

Research focused on introducing elementary school students to computer science concepts has been conducted since the 1970s and 1980s, with Papert [29], Clements [6], and other researchers interested in Logo [24] being notable contributors. Due to long interest in this topic, there is strong evidence that students as young as Kindergarteners can engage with computer science topics such as sequencing and debugging [e.g., 11, 12] and older elementary school students can engage with more complex topics such as synchronization and efficiency [e.g., 10, 32].

Fueled in part by the recent CS For All movement, there is now greater interest in not only what computer science topics students can tackle, but also with which aspects of computer science all students should have familiarity. To that end, computer science experts such as Wing [36], Guzdial [18], and Armoni and GalEzer [2] have described computational thinking and computer science in various ways and attempted to articulate what

\footnotetext{
Permission to make digital or hard copies of all or part of this work for personal or classroom use is granted without fee provided that copies are not made or distributed for profit or commercial advantage and that copies bear this notice and the full citation on the first page. Copyrights for components of this work owned by others than ACM must be honored. Abstracting with credit is permitted. To copy otherwise, or republish, to post on servers or to redistribute to lists, requires prior specific permission and/or a fee. Request permissions from Permissions@acm.org. SIGCSE '17, March 08-11, 2017, Seattle, WA, USA (C) 2017 ACM. ISBN 978-1-4503-4698-6/17/03...\$15.00 DOI: http://dx.doi.org/10.1145/3017680.3017772
}

computational thinking or computer science concepts and skills students should learn.

Both of these bodies of work - research with students and theoretical discussions from experts - are valuable when exploring questions about how to best bring CS to all. In this paper, we bring these two bodies of literature together to analyze how well expert theories about potential computer science learning goals align with the learning goals that have been researched with students and use this comparison to suggest possible topics for future research.

\section{RELATED WORK}

Other researchers have conducted reviews of computer science education and computational thinking literature. Some reviews summarize particular bodies of work or aspects of the field, such as Clements and Sarama's review of work with Logo [7] or Robles' review of work with Scratch [30]. Other reviews aim to develop frameworks, taxonomies, or definitions. For example, Weintrop et al. reviewed computer science and engineering literature to categorize the computational thinking practices applied in science, technology, engineering, and mathematics (STEM) disciplines [33].

Still other reviews aim to articulate the state of the computer science education field. For example, Grover and Pea [15] synthesized reactions and responses to Wing's [36] seminal description of computational thinking in order to identify and prioritize future research agendas. Lye and Koh analyzed a collection of intervention studies to summarize trends in empirical computer science education research and suggested research methodologies that could fill the gaps [23].

Our review had several purposes, but in this article we discuss an analysis related to the third purpose above: describing the current state of research on CS education in K-8 and identifying fruitful topics for future study. Specifically, we review scholarly literature to identify learning goals discussed as key to developing an understanding of computer science and any evidence (or lack thereof) of the appropriateness of these goals for students in K-8.

The remainder of this paper is divided into four sections. First, we describe our methods for finding the literature and extracting the learning goals. Second, we discuss the results of our analysis of which learning goals have been researched with students and which remain only theoretical. Third, we discuss potential implications of the analysis for future work. Lastly, we note the limitations of the study. 


\section{METHODS}

We conducted this study in four steps: gather pertinent literature, extract explicit and implicit learning goals, tag by type of support, and analyze fit between the theoretical and research-based goals.

\subsection{Sources of Literature}

To find pertinent literature, we first compiled a list of articles that cited Wing's [36] seminal paper on computational thinking. We then expanded the list via keyword searches of the Educational Research Information Center database. The keywords were "computational thinking," "computer science education," "computer science domains," "computer science activities," and "computer science pedagogy," with the additional signifiers "K5," "K-8," and "K-12" appended to each preceding term.

Via examination of abstracts, we retained articles that (1) discuss definitions of computer science and computational thinking and attempt to break it into components, (2) discuss or describe tools and interventions that focus on computer science education in $\mathrm{K}$ 8 , and/or (3) are empirical studies of either of the preceding.

To assemble a second source of evidence, we applied the same search criteria to the last 10 years of the proceedings Special Interest Group on Computer Science Education (SIGCSE) Technical Symposium and the Innovation and Technology in Computer Science Education (ITiCSE) conference, discarding any article that had already been reviewed, did not directly address K8 , or did not include any direct work with students. These more stringent exclusion criteria were applied to the second collection of literature in order to focus our efforts at this later stage on finding goals with student support, as described in Section 3.3. We reviewed a subset of these additional articles in the same manner as the articles in the first group. We performed keyword searches on the remainder, as discussed in Section 3.4.

\subsection{Extraction of Learning Goals}

To extract learning goals from our body of scholarly literature, we adopted the following definition of learning goal:

A learning goal is any explicit statement or implicit endorsement of what students can or should be able to do in relation to computer science.

Example heuristics for identifying learning goals that meet this definition are shown in Table 1. When possible, we recorded verbatim text from the article, but minor edits in word form or tense were often made to make sure the resulting text read like a goal and could be understood out of context. Each article was independently reviewed by at least two researchers, who subsequently met to resolve discrepancies.

Table 1. Heuristics for extracting learning goals

\begin{tabular}{|c|c|c|}
\hline $\begin{array}{c}\text { Explicit } \\
\text { Statement }\end{array}$ & $\begin{array}{c}\text { What students } \\
\text { can do }\end{array}$ & $\begin{array}{c}\text { What students } \\
\text { should be } \text { able to do }\end{array}$ \\
\hline $\begin{array}{c}\text { topics that students } \\
\text { successfully } \\
\text { completed }\end{array}$ & $\begin{array}{c}\text { Description of a } \\
\text { taxonomy of CS } \\
\text { concepts to be taught } \\
\text { in K-12 }\end{array}$ \\
\hline Endorsement & $\begin{array}{c}\text { Aggregate analyses } \\
\text { of student work } \\
\text { samples }\end{array}$ & $\begin{array}{c}\text { Description of the } \\
\text { most important or } \\
\text { foundational aspects } \\
\text { of computer science }\end{array}$ \\
\hline
\end{tabular}

\subsection{Definition of Support Types}

As we extracted and articulated learning goals, we tagged each goal with the type of support that the article offered for the goal. We describe the three support types here.

We tagged a goal with student support if the authors described evidence that students of particular ages were able to engage with the learning goal. Evidence could take the form of assessments, observations, or analysis of student work. Lab studies, classroom studies, and post-hoc student work analyses were included.

We tagged a goal with literature support if researchers documented discussion of the goal in other literature. Typically, goals with the literature tag came from literature review articles.

We tagged a goal with theoretical support if the article authors described the goal and/or its appropriateness for students without citing any particular evidence other than their own expertise or work with learners outside the target student population (e.g., teachers or other adults).

\subsection{Analysis of Fit}

After documenting and tagging all goals, we executed a by-hand analysis of how the goals with only theoretical or literature support matched onto the goals with student support. We examined each goal with theoretical or literature support and searched the goals with student support to find a goal with the same or similar meaning.

We sorted the theoretical or literature-supported goals in each group (matched to a student-supported goal and not matched) into categories. We searched the unreviewed articles from the second body of literature (see Section 3.1) for keywords related to the categories of unmatched goals in an effort to find any additional work with these goals. We used the results of the keyword searches to enrich the discussion of results in Section 5.

\section{RESULTS}

We performed reviews of 108 articles, 85 of which contained at least one learning goal. From these articles we articulated 678 learning goals. Table 2 shows the distribution of these goals across the support types.

Table 2. Distribution of goals across support type

\begin{tabular}{|c|c|c|c|}
\hline & $\begin{array}{c}\text { Student } \\
\text { Support }\end{array}$ & $\begin{array}{c}\text { Literature } \\
\text { Support }\end{array}$ & $\begin{array}{c}\text { Theoretical } \\
\text { Support }\end{array}$ \\
\hline $\begin{array}{c}\text { Goal } \\
\text { Count }\end{array}$ & 405 & 74 & 199 \\
\hline Percent & $60 \%$ & $11 \%$ & $29 \%$ \\
\hline
\end{tabular}

Of the 273 goals with theoretical or literature support, $210(77 \%)$ were matched with a student-supported goal, while $63(23 \%)$ were left without a match. We summarize the student-matched and unmatched goals in turn.

\subsection{Goals Supported by Research with Students}

Of the 210 theoretical or literature-supported goals we matched to goals with student support, $130(62 \%)$ could be grouped into categories with at least 12 examples. The categories, and the number of goals in each, are listed in Table 3. In the text that follows, we describe the categories and give one example of a theoretical goal in the category and a matched goal with student support. Goal text surrounded by quotation marks is taken directly from the article from which the goal was extracted. 
Table 3. Categories of matched goals

\begin{tabular}{|c|c|}
\hline Category & Goal Count \\
\hline Implementing Code & 25 \\
\hline Evaluating Solutions & 23 \\
\hline Matching Problems to Solutions & 19 \\
\hline Code Reading & 15 \\
\hline Abstracting Away Details & 12 \\
\hline Conditionals and Flow of Control & 12 \\
\hline Loops & 12 \\
\hline Variables, Data Structures, and Input & 12 \\
\hline
\end{tabular}

Implementing Code: These goals deal with translating common language or pseudocode into machine language or the skills needed to do so.

Example theoretical goal: Translate "a very specific instruction described in a textual or pseudocode format" into a programming language. [31]

Matched goal with student support: Purposefully choose programming instructions to match actions. [12]

Evaluating Solutions: These goals deal with evaluating programs in terms of their efficiency and effectiveness at accomplishing the intended task, either while programming (for iterative improvement) or with respect to a completed program.

Example theoretical goal: "Test that the solution is efficient (complexity considerations)." [2]

Matched goal with student support: "Count the number of steps (or commands) of a solution" and "find a better alternative in terms of total number of steps." [11]

Matching Problems to Solutions: These goals deal with recognizing familiar problem structures and recognizing that a solution has applicability to a wider class of problems.

Example theoretical goal: "Identify common patterns between older and newer problem-solving tasks". [1]

Matched goal with student support: "[R]ecognize and abstract the coding pattern from their first solution to solve the remaining two challenges." [32]

Code Reading: These goals deal with interpreting existing code and tracing its paths of execution.

Example theoretical goal: "[U]nderstand an existing piece of code." [32]

Matched goal with student support: Read and scrutinize "the original code" to discern what commands mean. [21]

Abstracting Away Details: These goals deal with simplifying problem situations to focus on the details most relevant to a computational solution.

Example theoretical goal: Identify "the critical aspects of the environment and the required system while neglecting the irrelevant." [20]

Matched goal with student support: "[A]bstract out the agents present in the interaction while preserving the interaction itself." [5]
Conditionals and Flow of Control: These goals deal with interpreting, implementing, and understanding the purpose of conditional control structures.

Example theoretical goal: "[K]now what conditional branching is and how it affects the flow of execution." [22]

Matched goal with student support: "[C]reate different pathways in programs using conditional statements." [16]

Loops: These goals deal with understanding the basic idea of a loop and implementing loops.

Example theoretical goal: Use "loops." [3]

Matched goal with student support: Use a "loop statement." [34]

Variables, Data Structures, and Input: These goals deal with understanding how to store and handle user- or programmerentered data.

Example theoretical goal: Achieve a basic understanding of "input [and] variables." [13]

Matched goal with student support: Understand "programming constructs like ... variables." [4]

The remaining matched goals did not pool into categories of more than 12 goals, but included planning programs, communicating about computing, and understanding concurrency, decomposition, and object-oriented programming.

\subsection{Goals Theorized but Not Yet Supported}

Of the 63 theoretical or literature-supported goals that we were not above to match to a goal with student support, 12 dealt with specific aspects of game design, and another four dealt with similarly specific skills applicable only in a few contexts. These 16 goals were discarded for their specificity. We sorted the remaining 47 unmatched goals into six categories of two or more goals. We summarize these categories in Table 4. Category descriptions and example goals follow the table.

Table 4. Categories of unmatched goals

\begin{tabular}{|c|c|}
\hline Category & Goal Count \\
\hline Designing Solutions & 20 \\
\hline Using Computational Tools & 13 \\
\hline Matching Problems to Devices & 5 \\
\hline Assessing Computational Models & 4 \\
\hline Avoiding Repeated Code & 3 \\
\hline Testing Boundary Cases & 2 \\
\hline
\end{tabular}

Designing Solutions: These goals deal with high-level planning of a computational solution, usually before coding.

Example theoretical goal: "[S]tate problems clearly and unambigously." [2]

Using Computational Tools: These goals deal with using computational solutions that the student did not necessarily design or create and interpreting the results, as well as evaluating the impact of computational tools on society.

Example literature-supported goal: Use computational tools to "manipulate datasets" to support further investigation. [33] 
Matching Problems to Devices: These goals deal with evaluating device options for a specific purpose.

Example theoretical goal: Determine the difficulty of a particular problem in relation to a given machine. [36]

Assessing Computational Models: These goals deal with evaluating the fit between a model and the phenomenon it is intended to model.

Example theoretical goal: "Assess how well" a computational "model matches reality." [9]

Avoiding Repeated Code: These goals deal with recognizing the need for or advantage of eliminating repeated code.

Example theoretical goal: Recognize when it is not desirable to "repeat code in the same project." [26]

Testing Boundary Cases: These goals deal with considering not only the typical cases, but also those on the boundary when designing and testing solutions.

Example theoretical goal: Consider "edge cases and failure cases" when defining abstractions. [35]

\section{DISCUSSION}

Research exists in major computer science education research venues for core concepts in programming, including loops, conditionals, and variables, and also for broader computational thinking concepts, such as recognizing familiar solution structures. However, we see gaps in mainstream computer science education venues for subtler topics, such as when to use particular programming techniques, and items outside of the narrow definition of computer science but within broader definitions of computational thinking, such as design considerations. This provides opportunities to explore whether, when, and to what depth these concepts should be introduced in K-8. Here, we discuss the six categories of learning goals without associated empirical or exploratory studies with students.

\subsection{Designing Solutions}

While significant bodies of research examine K-8 students' abilities to create the code for solutions, evaluate the effectiveness of solutions, and match well-defined computational problems to solutions (see the first three categories in Table 3), much less attention has been given to these students' abilities to navigate from a real-world problem to the beginning of a computational solution. One component skill in this process is the identification of relevant details, as captured in the Abstracting Away Details category (Table 3). This Designing Solutions category captures other related ideas that, according to our analysis, have yet to be explored with students, including clearly stating problems [2], reformulating problems so they can be solved computationally [36], and avoiding implementation constraints [20].

It is significant that of the 20 goals in this category, seven came from Weintrop et al.'s [33] framework for computational thinking in STEM disciplines. This seems to suggest that goals related to designing solutions would be well suited - and indeed, may also have been researched - in integrated courses rather than in CSspecific courses and informal education efforts that were the focus of this review. Should CS-focused efforts take a more applied approach, and include more aspects of design that are not directly related to coding? If so, at what age level is this appropriate? These are interesting questions for the CS education community to explore.

\subsection{Using Computational Tools}

Most of the learning goals we extracted from our body of CS education literature have to do with some aspect of the creation of a computational artifact. By contrast, this category of 13 goals deals with the use of computational artifacts, or tools, that students may or may not have created themselves. We speculate that this category has not been given particular attention because use of computational tools can be considered a component of computer literacy, and the CS education community has made efforts to help educators understand how computer science, and computational thinking, are bigger than knowing how to use a computer.

This begs the question - where does the line between computer literacy and computational thinking lie? Our discovery of 13 unsupported learning goals, most of which are related to the use of computational models, not simple word processing or spreadsheets, led us to ponder the role that the use of computational tools might play in K-8. Might using a variety of computational tools in $\mathrm{K}-8$, and discussing their affordances, serve as a useful prerequisite to learning topics related to creation of computational artifacts in later grades? If so, how might the use of computational tools be framed for K-8 students to support them in making connections in later grades?

\subsection{Matching Problems to Devices}

Five learning goals discussed in $[33,36,10]$ go past the mechanics of writing programs to the capability of different devices to solve problems. This is clearly a more advanced topic, requiring understanding the limitations of different devices and tools. At least two experts theorize that this is within the realm of computer science, but is it within the aspects of computer science that all students should learn? If this is a part of CS that we want to teach to all, is it worthwhile or appropriate to address it in $\mathrm{K}-8$ ? While we did not find any studies addressing this idea directly, two studies provide some insight.

A study of how middle schoolers think about algorithmic efficiency found that some students naturally consider available equipment when deciding on an algorithmic approach to solving a problem [14]. This suggests that students of this age may have the ability to think critically about devices.

On the other hand, an examination of middle schoolers' responses to the question, "What is a computer?", found that students tended to focus on the specifics of devices, with less attention to defining features of computers [17]. The researchers argue, as a result, for a focus in middle school on the broader ideas of computing rather than on devices. This suggests that goals related to device choice may be more appropriate for high school and beyond.

\subsection{Assessing Computational Models}

Interestingly, we discovered several theoretical or literaturesupported goals related to creating computational models, with a focus on identifying relevant details (e.g., Model "the relevant aspects of a problem to make it tractable" [36]). We were able to match these to student-supported goals (e.g., Identify "the relevant agents with appropriate properties and behaviors" when defining a computational model [4]). In contrast, we also discovered four theoretical or literature-supported goals related to assessing computational models, and we were not able to match these to student-supported goals.

When coupled with the lack of student support for goals related to the use of computational tools (including models, see Section 5.2), we see that the creation of computational models is treated 
differently from the use and assessment of those models. From a superficial perspective, creating a computational model requires programming skills, whereas use and assessment do not. However, we see at least two arguments for use and assessment of computational models to be included in $\mathrm{K}-8 \mathrm{CS} / \mathrm{CT}$ instruction.

First, the use and assessment of software are important parts of the software design process. Computational thinking refers to a broad view of computer science, and includes a larger set of skills than programming. Thus, from a computational thinking perspective, it makes sense to include use and assessment of models.

Second, the Common Core State Standards [27] and the Next Generation Science Standards [28] contain calls for students to evaluate and interpret models in K-8. Therefore use and assessment of computational models may provide a logical integration point for $\mathrm{CS} / \mathrm{CT}$ instruction in these grades.

\subsection{Avoiding Repeated Code}

While we discovered ample literature that explored how K-8 students handle the mechanics of function calls and loops, we did not find any evidence of early instruction about whether to create a function or a loop. How many loop iterations justifies a loop? How many times do you need to reuse code to justify a function call? How many instructions should it include? These are subtle issues related to the broader idea of creating clean, efficient, and readable code. At what age should we transition from teaching students the mechanics of particular constructs to strategies on when to use them? Do these strategies need to be explicitly taught, or are they naturally developed through practice? These questions remain unanswered by existing research.

\subsection{Testing Boundary Conditions}

At least one set of experts has theorized that taking account of all possible conditions is a worthwhile learning goal for computer science (Devise "suitable test cases" when testing and debugging a program [8]), and at least one research team has investigated students' work with this concept (Systematically choose "examples of input that" represent "general cases" to test an algorithm [19]). In addition, our review identified research that explored students' use of if/else statements, showing that some students in late elementary school can effectively use them [34]. We acknowledge this as a worthy beginning to building understanding of the need to specify what to do in all conditions. By their nature, if/else statements prompt students to exhaust possibilities. However, because of this automatic exhaustion, use of simple if/else statements does not show evidence of specifically attending to the edge and boundary cases, as highlighted in this pair of unmatched goals.

An analysis of novice ninth-graders' work in Scratch revealed that these students did sometimes consider boundary conditions, but often handled them through the use of a separate script rather than integrating them into the original conditional, suggesting they are added as an afterthought [25]. This is an example of what the researchers call extremely fine-grained programming (EFGP), and they point out that these techniques can lead to bugs that are particularly hard to identify and fix. Since lack of upfront consideration of boundary cases been identified as a common problem and not intuitive, perhaps we should consider at what age this concept should be introduced, though we must be careful to match the developmental age of the students. Younger students are not thorough in many things, so it would be counterproductive to expect thoroughness in programming.

\section{CONCLUSIONS AND LIMITATIONS}

Our purpose in this review is not to specify what should be researched in K-8 computer science education, but rather to point out discrepancies between theorized computational thinking goals and what is being researched in the mainstream computer science education community. In some cases, the seemingly unresearched goals may have been researched with students older than eighth grade, and since some categories deal with applications of computer science, some goals may have been researched within other bodies of work. The goal-extraction and matching procedures, which were dependent on verbatim extraction of text and keyword searches, also may have missed learning goals or matches that are similar in meaning but different in articulation. We report our analysis to provoke discussion, but not in support of immediate or specific research agendas.

\section{ACKNOWLEDGMENTS}

This material is based on work supported by the National Science Foundation under Award \#1542828 and Award \#1240985. Any opinions, findings, and conclusions or recommendations expressed are those of the authors and do not necessarily reflect those of the National Science Foundation.

\section{REFERENCES}

[1] Angeli, C., Voogt, J., Fluck, A., Webb, M., Cox, M., MalynSmith, J., and Zagami, J. 2016. A K-6 computational thinking curriculum framework: Implications for teacher knowledge. Educational Technology \& Society, 19(3), 47-57.

[2] Armoni, M. and Gal-Ezer, J. 2014. Early computing education: why? what? when? who? ACM Inroads, 5(4), 5459. DOI=http://dx.doi.org/10.1145/2684721.2684734

[3] Barr, V. and Stephenson, C. 2011. Bringing computational thinking to K-12: what is involved and what is the role of the computer science education community?. Acm Inroads, 2(1), 48-54. DOI=http://dx.doi.org/10.1145/1929887.1929905

[4] Basu, S., Kinnebrew, J. S., and Biswas, G. 2014. Assessing student performance in a computational-thinking based science learning environment. In International Conference on Intelligent Tutoring Systems, 476-481. Springer International Publishing. DOI=http://dx.doi.org/10.1007/9783-319-07221-0_59

[5] Basawapatna, A. R., Repenning, A., and Lewis, C. H. 2013. The simulation creation toolkit: an initial exploration into making programming accessible while preserving computational thinking. In Proceedings of the 44th ACM Technical Symposium on Computer Science Education, 501506. ACM. DOI=http://dx.doi.org/ $10.1145 / 2445196.2445346$

[6] Clements, D. H. 2002. Computers in early childhood mathematics. Contemporary Issues in Early Childhood, 3(2), 160-181. DOI=http://dx.doi.org/0.2304/ciec.2002.3.2.2

[7] Clements, D. H. and Sarama, J. 1997. Research on Logo: A decade of progress. Computers in the Schools, 14(1-2), 9-46. DOI= http://dx.doi.org/10.1300/J025v14n01_02

[8] Duncan, C., Bell, T., and Tanimoto, S. 2014. Should your 8year-old learn coding? In Proceedings of the 9th Workshop in Primary and Secondary Computing Education, 60-69. ACM. DOI= http://dx.doi.org/10.1145/2670757.2670774

[9] Dwyer, H., Boe, B., Hill, C., Franklin, D., and Harlow, D. 2013. Computational Thinking for Physics: Programming Models of Physics Phenomenon in Elementary School. In 
Engelhardt, Churukian, \& Jones (Eds.) 2013 PERC Proceedings, 133-136. College Park, MD: American Association of Physics Teachers.

[10] Dwyer, H., Hill, C., Carpenter, S., Harlow, D., and Franklin, D. 2014. Identifying elementary students' pre-instructional ability to develop algorithms and step-by-step instructions. In Proceedings of the 45th ACM technical symposium on Computer science education, 511-516. ACM.

[11] Fessakis, G., Gouli, E., and Mavroudi, E. 2013. Problem solving by 5-6 years old kindergarten children in a computer programming environment: A case study. Computers \& Education, 63, 87-97.

[12] Flannery, L. P. and Bers, M. U. 2013. Let's dance the "robot hokey-pokey!" children's programming approaches and achievement throughout early cognitive development. Journal of research on technology in education, 46(1), 81101.

DOI=http://dx.doi.org/10.1080/15391523.2013.10782614

[13] Franklin, D., Conrad, P., Boe, B., Nilsen, K., Hill, C., Len, M., Dreschler, G., Aldana, G., Almeida-Tanaka, P., Kiefer, B., and Laird, C. 2013. Assessment of computer science learning in a scratch-based outreach program. In Proceeding of the 44th ACM technical symposium on Computer science education, 371-376. ACM.

DOI=http://dx.doi.org/10.1145/2445196.2445304

[14] Friend, M. and Cutler, R. 2013. Efficient egg drop contests: How middle school girls think about algorithmic efficiency. In Proceedings of the ninth annual international ACM conference on International computing education research, 99-106. ACM.

DOI=http://dx.doi.org/10.1145/2493394.2493413

[15] Grover, S. and Pea, R. 2013. Computational Thinking in $\mathrm{K}-$ 12 A Review of the State of the Field. Educational Researcher, 42(1), 38-43. DOI=http://dx.doi.org/ 10.3102/0013189X12463051

[16] Grover, S., Pea, R., and Cooper, S. 2015. Designing for deeper learning in a blended computer science course for middle school students. Computer Science Education, 25(2), 199-237.

[17] Grover, S., Rutstein, D., and Snow, E. 2016. What Is A Computer: What do Secondary School Students Think? In Proceedings of the 47th ACM Technical Symposium on Computing Science Education, 564-569. ACM. DOI= http://dx.doi.org/10.1145/2839509.2844579

[18] Guzdial, M. 2008. Education Paving the way for computational thinking. Communications of the ACM, 51(8), 25-27. DOI=http://dx.doi.org/10.1145/1378704.1378713

[19] Kolikant, Y. B. D., and Pollack, S. 2004. Establishing computer science professional norms among high-school students. Computer Science Education, 14(1), 21-35.

[20] Kramer, J. 2007. Is Abstraction the Key to Computing? Communications of the ACM, 50(4), 36-42. DOI= http://dx.doi.org/10.1145/1232743.1232745

[21] Lee, M. J., Bahmani, F., Kwan, I., LaFerte, J., Charters, P., Horvath, A., Luor, F., Cao, J., Law, C., Beswetherick, M., and Long, S. 2014. Principles of a debugging-first puzzle game for computing education. In 2014 IEEE Symposium on Visual Languages and Human-Centric Computing (VL/HCC), 57-64. IEEE.
[22] Liu, J., Lin, C. H., Wilson, J., Hemmenway, D., Hasson, E., Barnett, Z., and Xu, Y. 2014. Making games a snap with Stencyl: a summer computing workshop for K-12 teachers. In Proceedings of the 45th ACM technical symposium on Computer science education, 169-174. ACM. DOI=http://dx.doi.org/10.1145/2538862.2538978

[23] Lye, S. Y. and Koh, J. H. L. 2014. Review on teaching and learning of computational thinking through programming: What is next for K-12?. Computers in Human Behavior, 41, 51-61. DOI= http://dx.doi.org/10.1016/j.chb.2014.09.012

[24] Maddux, C. D. and Johnson, D. L. (Eds.). 1997. Logo: A Retrospective. New York: Hawthorne Press, Inc.

[25] Meerbaum-Salant, O., Armoni, M., and Ben-Ari, M. 2011. Habits of programming in scratch. In Proceedings of the 16th annual joint conference on Innovation and technology in computer science education, 168-172. ACM. DOI= http://dx.doi.org/10.1145/1999747.1999796

[26] Moreno, J. and Robles, G. 2014. Automatic detection of bad programming habits in scratch: A preliminary study. In 2014 IEEE Frontiers in Education Conference (FIE) Proceedings, 1-4. IEEE. DOI=http://dx.doi.org/10.1109/FIE.2014.7044055

[27] National Governors Association Center for Best Practices and Council of Chief State School Officers. 2010. Common Core State Standards for Mathematics. Washington, DC: Authors. From http://www.corestandards.org/Math/

[28] National Research Council, National Science Teachers Association, American Association for the Advancement of Science, and Achieve. 2016. Next Generation Science Standards. From http://www.nextgenscience.org/

[29] Papert, S. 1980. Mindstorms: Children, computers, and powerful ideas. New York: Basic Books, Inc.

[30] Robles, G. 2016. Code to learn with Scratch? A systematic literature review. In 2016 IEEE Global Engineering Education Conference (EDUCON), 150-156. IEEE. DOI=http://dx.doi.org/10.1109/EDUCON.2016.7474546

[31] Santos, A., Gomes, A., and Mendes, A. 2013. A taxonomy of exercises to support individual learning paths in initial programming learning. In 2013 IEEE Frontiers in Education Conference (FIE), 87-93. IEEE.

[32] Seiter, L. 2015. Using SOLO to Classify the Programming Responses of Primary Grade Students. In Proceedings of the 46th ACM Technical Symposium on Computer Science Education, 540-545. ACM.

[33] Weintrop, D., Beheshti, E., Horn, M., Orton, K., Jona, K., Trouille, L., and Wilensky, U. 2016. Defining computational thinking for mathematics and science classrooms. Journal of Science Education and Technology, 25(1), 127-147.

[34] Werner, L., Denner, J., and Campe, S. 2015. Children programming games: a strategy for measuring computational learning. ACM Transactions on Computing Education (TOCE), 14(4), 24. DOI=http://dx.doi.org/10.1145/2677091

[35] Wing, J. M. 2008. Computational thinking and thinking about computing. Philosophical transactions of the royal society of London A: mathematical, physical and engineering sciences, 366(1881), 3717-3725.

[36] Wing, J. M. 2006. Computational thinking. Communications of the ACM, 49(3), 33-35. 